Check for updates

Cite this: RSC Adv., 2019, 9, 34720

Received 28th August 2019 Accepted 1st October 2019

DOI: $10.1039 / c 9 r a 06807 d$

rsc.li/rsc-advances

\section{Evolutionary approaches in protein engineering towards biomaterial construction}

\author{
Brindha J., ${ }^{a}$ Balamurali M. M.*a and Kaushik Chanda (iD *b
}

The tailoring of proteins for specific applications by evolutionary methods is a highly active area of research. Rational design and directed evolution are the two main strategies to reengineer proteins or create chimeric structures. Rational engineering is often limited by insufficient knowledge about proteins' structurefunction relationships; directed evolution overcomes this restriction but poses challenges in the screening of candidates. A combination of these protein engineering approaches will allow us to create protein variants with a wide range of desired properties. Herein, we focus on the application of these approaches towards the generation of protein biomaterials that are known for biodegradability, biocompatibility and biofunctionality, from combinations of natural, synthetic, or engineered proteins and protein domains. Potential applications depend on the enhancement of biofunctional, mechanical, or other desired properties. Examples include scaffolds for tissue engineering, thermostable enzymes for industrial biocatalysis, and other therapeutic applications.
${ }^{a}$ Department of Chemistry, School of Advanced Science, Vellore Institute of Technology, Chennai Campus, Vandalur-Kelambakkam Road, Chennai-600 127, Tamil Nadu, India. E-mail: mmbala@gmail.com
${ }^{b}$ Department of Chemistry, School of Advanced Science, Vellore Institute of Technology, Vellore-632014, Tamil Nadu, India. E-mail: chandakaushik1@gmail. com

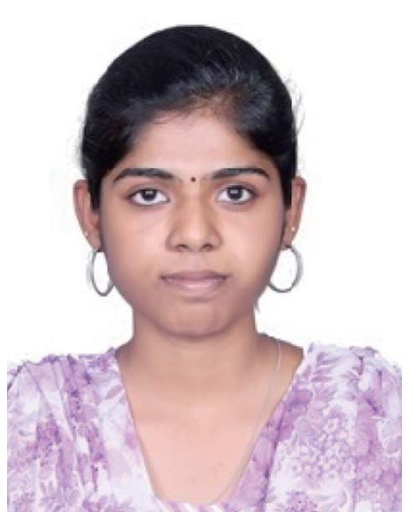

Brindha J. is a PhD scholar at Vellore institute of technology, Chennai campus. Currently she is working on creating simple strategies for generating library of protein hybrids and also protein biomaterials.

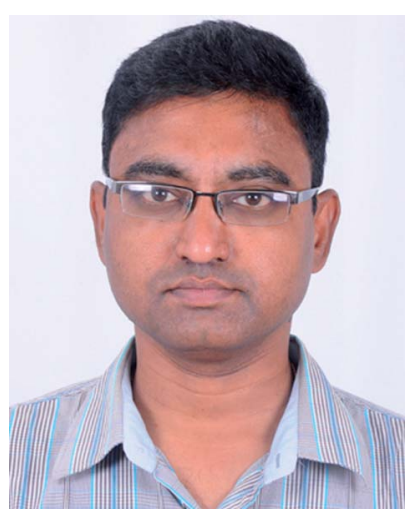

Dr Balamurali MM, was awarded the Master's degree in Chemistry, by Madurai Kamaraj University, Tamil Nadu, India in 1999. He pursued his doctoral research in Photophysical Chemistry at Indian Institute of Technology Kanpur, under the supervision of Prof. Sneh Kumar Dogra. In 2005, he was awarded the CSIR research associate fellowship and continued his postdoctoral research in Prof. Raghavan Varadarajan's group at Indian Institute of Science Bangalore. In 2007, he moved to University of British Columbia, Canada and in 2009 he joined Prof. Debkumar Pain's research group at New Jersey Medical School, USA and continued his interdisciplinary research respectively in Biophysical and Biochemistry. In 2011, he served as research scientist in DST India funded National Hub for Healthcare Instrumentation Development, Anna University, Chennai, India. Since 2013, he is continuing to serve Vellore Institute of Technology, India as Assistant Professor (Senior) in the Department of Chemistry. His research interests include Protein Engineering and Biophysical Chemistry. 


\section{Introduction}

Today, strategies for improving proteins' functionalities include immensely varying combinations of rational design along with random mutagenesis via directed evolution followed by screening. To move forward in this process of enhancing proteins' desirable properties, protein engineers ought to compare the two main protein engineering strategies - rational design and directed evolution, combine the effective methodologies, and successfully create protein variants with ease by employing various protein engineering methods. Proteins or enzymes obtained by directed evolution have found a firm place in industrial and therapeutic applications, but are still striving for improvement in other biomedical fields of application. To date, the demand for an efficient method to achieve improved biofunctionalities or modified thermodynamic properties persists. Rational design and directed evolution are the two approaches being employed to achieve this.

Engineered proteins with their enhanced biofunctionality/ other properties and ability to form hydrogels or other forms of biomaterials are becoming vital these days, for their potential applications in biomedical fields such as drug delivery, synthetic extracellular matrix materials for tissue engineering, ${ }^{1-4}$ etc. The history of biomaterials dates far back into ancient civilization. According to the first Consensus Conference of the European Society for Biomaterials (ESB) in 1976, a biomaterial was defined as 'an inert material used in medical applications, to connect with biological systems', which was later changed as 'a material that can combine biological systems to check, heal, improve or restore any part or function of the human body'. ${ }^{5}$ The subtle modification in the definition indicates that biomaterials have been evolving with the needs and challenges in healthcare. The capability to repair or replace

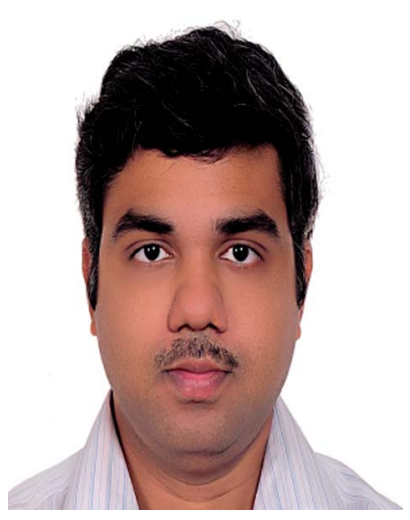

Dr Kaushik Chanda, obtained his MSc in Organic Chemistry from Gauhati University, Assam India in 2001. Subsequently worked as a Senior Research Fellow in ICAR-NATP funded project in St Anthonys College, Shillong, India from 2002-2005. In 2006, he moved to Taiwan for pursuing PhD in Applied Chemistry from National Chiao Tung University under the guidance of Prof Chung Ming Sun on a topic of Combinatorial Chemistry. After finishing his PhD in 2010, he moved to Department of Chemistry, National Tsing Hua University, Taiwan for NSC-postdoctoral fellowship in facet dependent organic catalysis with Prof Michael HY Huang. Now he is working as an Assistant Professor in Department of Chemistry, Vellore Institute of Technology, Vellore. His research interest includes the diversity oriented synthesis, anticancer drug design, drug delivery and nanocatalysis. damaged tissues or organs has enhanced the life expectancy of several individuals. Among the earliest were the use of waxes, glues and tissues, by the Indians and Chinese in restoring the missing parts of the body, and also the artificial body parts that were seen in Egyptian mummies. ${ }^{6}$ The requirement for basic research on implantable materials was initiated when physicians started using implants in medical field. ${ }^{7}$ Early biomedical implants were not successful because the critical concepts associated with infection, biomaterials, and the biological responses to those biomaterials were not fully understood. Until Joseph Lister's sterile surgical method ${ }^{8}$ was established in the 1860s, different metallic implants like pins, wires made up of iron, gold, silver etc. and tissue replacements failed due to contamination after implanting. Moreover, dislodgement, contamination with infectious agents at the association of implant and tissue, rupture and migration occurs with time when foreign implants are used. The development of biomaterials has evolved since then, from titanium that was reported to be biocompatible with bone. ${ }^{9}$ The calcium and phosphate ion immobilized titanium finds application as bone tissue implant by stimulation of the responses of pre-osteoblast cells. ${ }^{\mathbf{1 0}}$ Currently, biomaterials find a vast range of biomedical applications including prosthetic implants, ${ }^{\mathbf{1 1}, 12}$ drug delivery systems ${ }^{13,14}$ tissue engineering ${ }^{\mathbf{1 5 , 1 6}}$ and regenerative medicine. ${ }^{17,18}$

Biomaterials, as a multidimensional field has grown steadily since its outset with a constant influx of new concepts and advancements. Biomaterials have evolved since ancient times for the betterment of humans. The main goal during 1960s to 1970 s, in the design of first generation biomaterials was to keep a balance between mechanical and physical properties along with minimal toxicity to host tissue. ${ }^{19}$ The limitations within contemporary medicine led to the development of tissue engineering and regenerative medicine. With the progress in molecular biology concepts, recombinant DNA technology and genetic engineering, new path has been opened up for biomaterial design that can coordinate with the normal human physiology and integrate with human body. Various combinations of biomaterials with distinct properties come together as novel materials for their use in controlled drug delivery, gene therapy or therapeutics, tissue engineering applications, etc. Several generations of biomaterials have evolved with time and advancements in various branches of science. New smart biomaterials ${ }^{20,21}$ are being created by integrating various technical concepts and biological constituents with the aim of expanding its applications in human healthcare.

This review aims to highlight the two important protein engineering approaches - rational design and directed evolution along with selective examples that can pave way for their constitution into biomaterials. Here, the readers can also find a brief account on various protein based biomaterials used in biomedical applications. On the whole, this review will lead the readers to ponder about the possibilities of using protein engineering strategies and combinations of engineered proteins/protein domains, towards the creation of novel protein based biomaterials for use in biomedical field. 


\section{Protein engineering and biomaterial construction}

Protein engineering employs recombinant DNA technology to modify amino acid sequences, for designing new enzymes or proteins with modified or enhanced properties. Earlier protein engineering was known to depend on techniques like X-ray crystallography, chemical synthesis of DNA, computational modeling of protein structure and folding, etc. A combined approach involving protein crystal structure and chemical synthesis of genes has been the most practiced one for creating proteins with desired functions. ${ }^{22}$ The potential of protein engineering had been identified by then towards engineering biocatalysts with enhanced efficiency. ${ }^{23}$ In recent years, protein engineering methods and applications have become extensive and significant due to the advancements in recombinant DNA technology and high-throughput screening techniques. Protein engineering can be broadly classified under the following categories - rational design, de novo design and directed evolution. The first protein design was done rationally based on manual analysis of the existing protein sequences, amino acid charges and the desired structural geometry. ${ }^{24}$ Gutte et al. pioneered the protein design by rationally designing a 70 amino acid peptide analog of ribonuclease $\mathrm{S}$ with enzyme activity via solid phase synthesis. ${ }^{25}$ Rational design is effective only when the structure and/or folding mechanism of the proteins of interest are well-established. The limitation of these data about protein structure and mechanism of protein folding led to the use of other evolutionary methods like directed evolution. This method of directed evolution involve "random mutagenesis and selection" to achieve desired properties of the protein, ${ }^{26}$ but then the limitation roots in screening of the randomly evolved proteins. The manual analyses of protein designs was then replaced by a fully automated computational algorithm based de novo protein design which can screen a library of amino acid sequences for compatibility with the desired target design. ${ }^{27}$ Later, in the beginning of $21^{\text {st }}$ century, the potential of de novo enzyme engineering was established. ${ }^{28}$ This method includes computational rational design, from the scratch and not based on another similar parent protein associated with a substrate/reaction mechanism. The advantages of rational and directed evolution have been combined together, as localized/region specific random mutations to design proteins, often known as semi-rational protein engineering. ${ }^{29,30}$ An outline of the protein engineering strategies is given as a flowchart in Fig. 1.

Research on biomaterials, a multidisciplinary field is consistently expanding with substantial introduction of new ideas and approaches, particularly to aid human healthcare. Use of biomaterials dates back to a few decades and the demand for new reliable biomaterials has led to developments in this field. Natural proteins offer biofunctionality by mimicking the extracellular matrices in human body, thereby enabling biological interaction with the cells/tissues with lesser immunogenic responses as compared to other synthetic biomaterials.
Proteins also offer biodegradability to the biomaterials. In addition, proteins can also be engineered for controlled degradation, where the scaffold material degradation can be synchronized for tissue formation over a period of time. There is a shift from synthetic and natural biomaterials to hybrid biomaterials that have synergistic effect and improved characteristics suitable for use in drug delivery systems, implants, tissue engineering scaffolds, biosensors and other biomedical applications. Herein, we discuss the applications of various protein engineering strategies towards the generation of biomaterials and categorize them based on the source proteins used for their construction. The biomaterials constructed with a combination of well characterized natural proteins or peptide/ protein domains with known structure/function along with/ without synthetic/ceramic materials are known as rationally designed protein biomaterials. Whereas, those biomaterials constructed with random combinations of randomly evolved proteins/protein domains/ensembles with no prior structural data are known to be directed evolution based protein biomaterials.

\subsection{Evolution of proteins by rational engineering - towards biomaterial construction}

Rational design is one of the traditional strategies to engineer proteins with enhanced or desired properties. ${ }^{31}$ The process of rational design starts with choosing a suitable protein scaffold, identifying the important residues for modification, and screening of mutants followed by their characterization. In rational approach it is necessary to choose the protein scaffold based on prior knowledge of that protein's structure or by the structure of a homologous protein. The residues or regions to be changed in the protein scaffold are decided according to the function of the protein on hand as well as the anticipated function after rational designing. These modifications involve mutation, deletion, or insertion of one or several of the amino acids in the native protein sequence. This is carried out through rational engineering by site directed mutagenesis where amplification of variants occurs with mutated oligonucleotides by methods like megaprimer-based PCR, inverse PCR and overlap extension PCR. Gene truncation or deletions is also one another strategy to identify specific function of a domain or region. Alteration of functions by rational approaches ${ }^{32}$ can be achieved through single-point mutation, exchange of elements in secondary structure, exchange of whole domains, or generation of fusion proteins. ${ }^{33}$ For instance, the amino acid residues responsible for thermostability are identified by comparing the sequences of stable or less stable proteins. ${ }^{34}$ Multiple factor strategy has been designed rationally by the integration of three factors that affect the structure, including salt bridges, protein flexibility and protein surface as illustrated in Fig. 2. It was reported that mutants with a combination of multiple factors of thermostable sites were found to have doubled thermostability and also enhanced catalytic efficiency. These kinds of rational mutations could be applied towards construction of biomaterials as well. The significant strategies employed for the rationally engineered biomaterials and its applications are discussed below. 


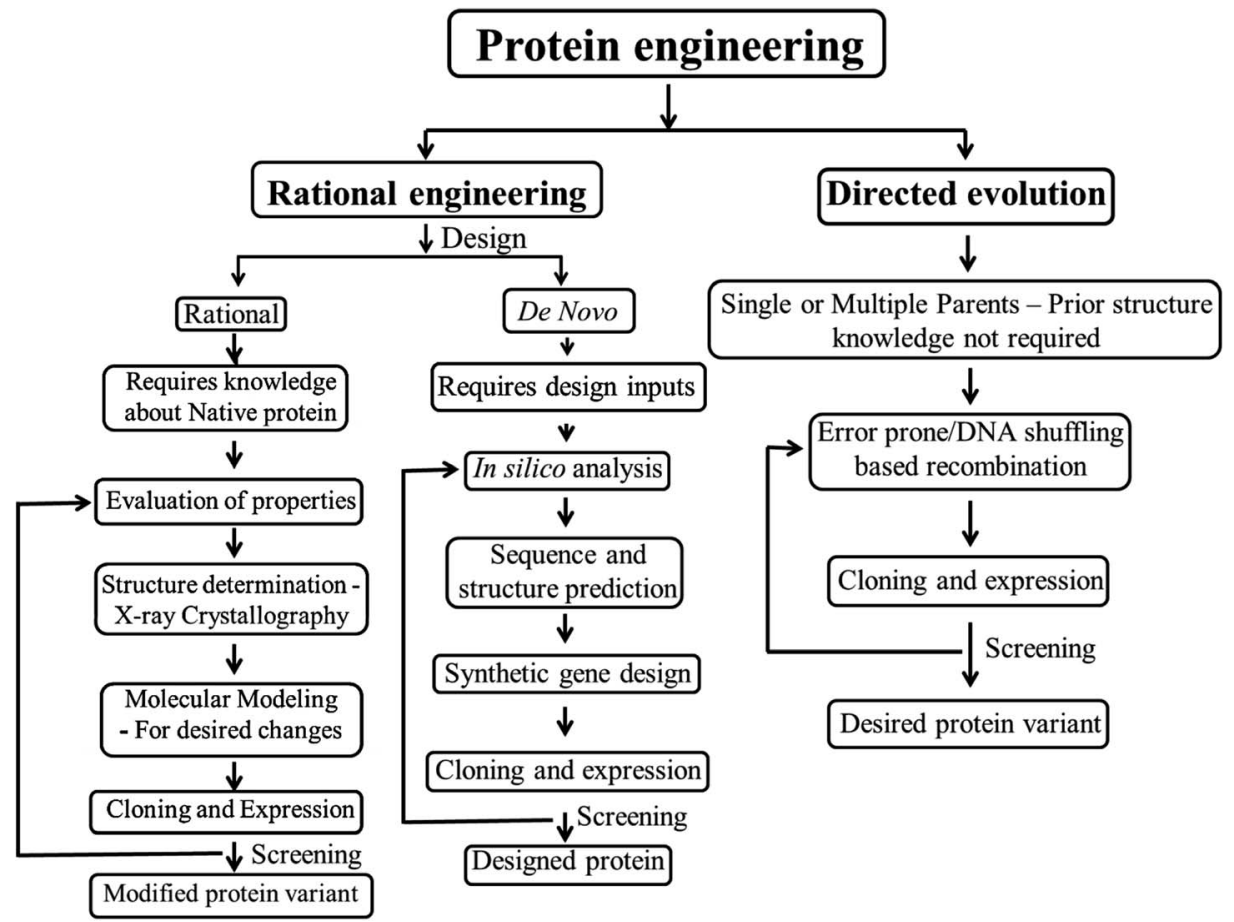

Fig. 1 Structural outline of protein engineering strategies.

- Rational designing of protein biomaterials include natural proteins because of their known bio functionality, biodegradability and biocompatibility, which are usually more preferred for biomedical applications. Natural proteins including collagen, silk/silk fibroin, keratin, gelatin, fibrinogen, fibrin, fibronectin, elastin, actin, myosin, resilin, titin, soy, zein, wheat gluten, casein, serum albumin, etc. are employed for biomaterial construction. Here we limit our discussion to protein biomaterials from natural proteins like collagen, silk, engineered/modular proteins and their combinations with synthetic polymers, ceramics or other proteins/peptides along with their biomedical applications. The Table 1 gives a list of significant biomedical applications along with the base material used.

- Two or more materials are rationally combined for their distinct composition, structure and other physical properties in rational designing of hybrid or semi synthetic biomaterials. It usually follows the approach of combining the biomaterials in the form of natural/synthetic biopolymers and/or bioceramics. The natural polymers are known to have weak mechanical properties and these can be enhanced by combination of inorganic hydroxyapatite or polymers like polycaprolactone.

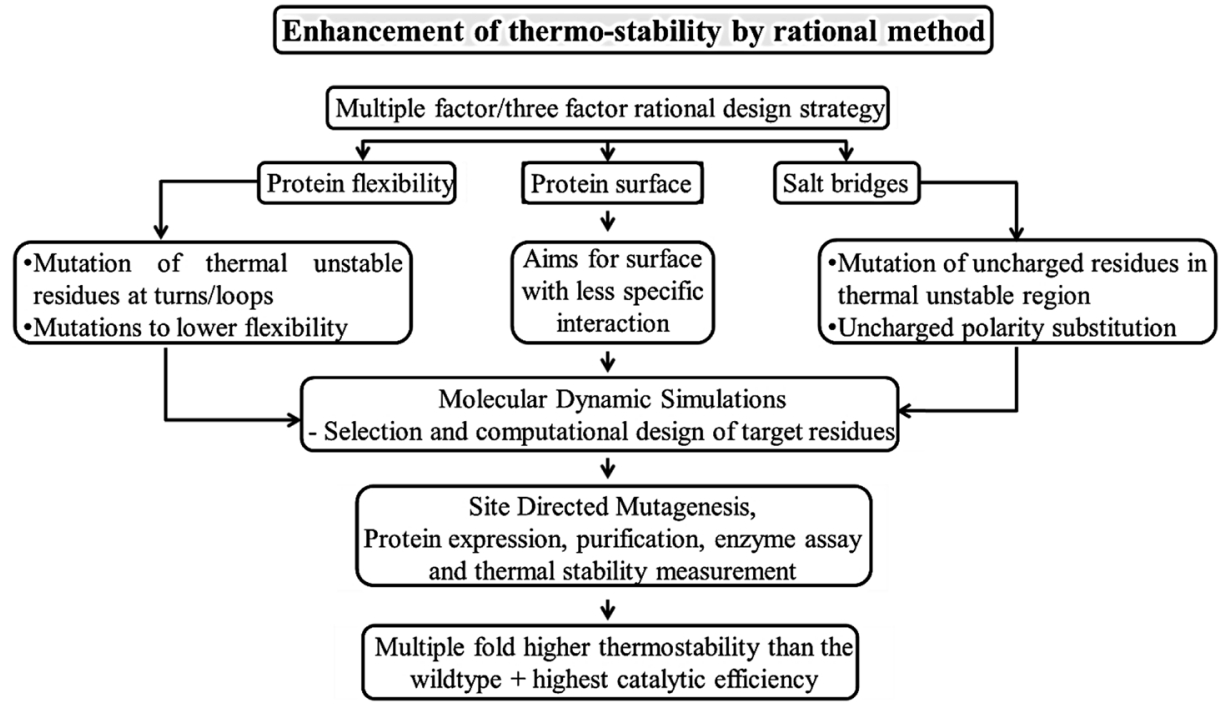

Fig. 2 Strategy to enhance the structural and functional properties of biomolecules. 
Table 1 List of most common biomedical applications with their respective base materials and selective references

\begin{tabular}{|c|c|c|}
\hline Biomedical Applications & Base materials & References \\
\hline \multirow[t]{2}{*}{ Wound healing } & - Collagen & 39 \\
\hline & - Chitosan nano-particles & 40 and 41 \\
\hline \multirow[t]{3}{*}{ Biological adhesives/sealants } & - Collagen, gelatin based & 43 \\
\hline & - Fibrin based & 44 \\
\hline & - Chitin and chitosan membranes & 39 \\
\hline \multirow{2}{*}{ Biodegradable sutures } & - Metal sutures & 49 \\
\hline & - Polymer sutures & 50 \\
\hline \multirow[t]{4}{*}{ Carriers in drug delivery systems } & - Albumin & 51 \\
\hline & - Plant proteins & 52 \\
\hline & - Chitosan and its nano composites & 53 \\
\hline & - Polymeric biomaterial and lipid based nanoparticles & 54 \\
\hline
\end{tabular}

- By means of genetic engineering, properties of proteins can be rationally tuned by incorporating functional sequences, unnatural amino acids, and specific peptide domains with unique properties forming combinatorial design and also formation of stimuli-induced systems. Also, as isolation of protein in large scale from natural sources is not affordable, genetically engineered proteins are developed with homogeneity. Modular proteins with a combination of silk-like-proteins and elastin-like-proteins by recombinant technology forms silkelastin-like-proteins, a stimuli-responsive system, which are found responsive for parameters like $\mathrm{pH}$, temperature, redox, ionic strength, electric fields and enzymatic stimuli, that can be used for controlled delivery of therapeutics. ${ }^{35}$ These rationally designed recombinant protein polymers possess tunable structure-function property, ${ }^{36}$ enhanced mechanical and elastic property, biocompatibility, degradability and target specificity.

- Rationally designed modular protein engineered biomaterials are another form of hybrid materials, that involves selection of desired peptide domains with desired functionality, designing of structural orientation of those peptide domains, selection of their amino acid sequences and encoding gene sequences, followed by cloning and polypeptide purification using a host organism ${ }^{37}$ as shown in Fig. 3. These protein engineered materials with known structure and function, ensures both tunability and biofunctionality required for a particular application, which cannot be customized in many native or synthetic materials. ${ }^{38}$

\subsubsection{Biomedical applications - rationally engineered protein biomaterials}

Wound healing. Several wound dressings with specific properties are being developed, to meet the healing requirements of the different kinds of wounds. More recently, nanofibrous matrices were developed using a combination of non-mulberry silk protein sericin, chitosan and polyvinyl alcohol, mimicking the structure of extracellular matrices. ${ }^{42}$ These matrices have proved to promote the growth of keratinocytes in vitro and wound healing in vivo with the formation of epithelial cells of skin along with angiogenesis. For the treatment of chronic wounds where the normal healing process has failed, biomaterials with mesenchymal stem cells have been used in the recent years. Soy protein was integrated with chitin to form a moisture retaining biomaterial ${ }^{59}$ that unites with the human mesenchymal stem cells derived from adipose tissue, resulting in the regeneration of wound tissues by enhanced anti-inflammatory effect due to indoleamine 2,3-dioxygenase production. Collagen $^{60}$ and chitosan ${ }^{39}$ based blends have also been largely exploited for wound dressing applications due to their promising biocompatibility. Also, gelatin films grafted with carboxy methylated guar gum incorporated with a natural antimicrobial

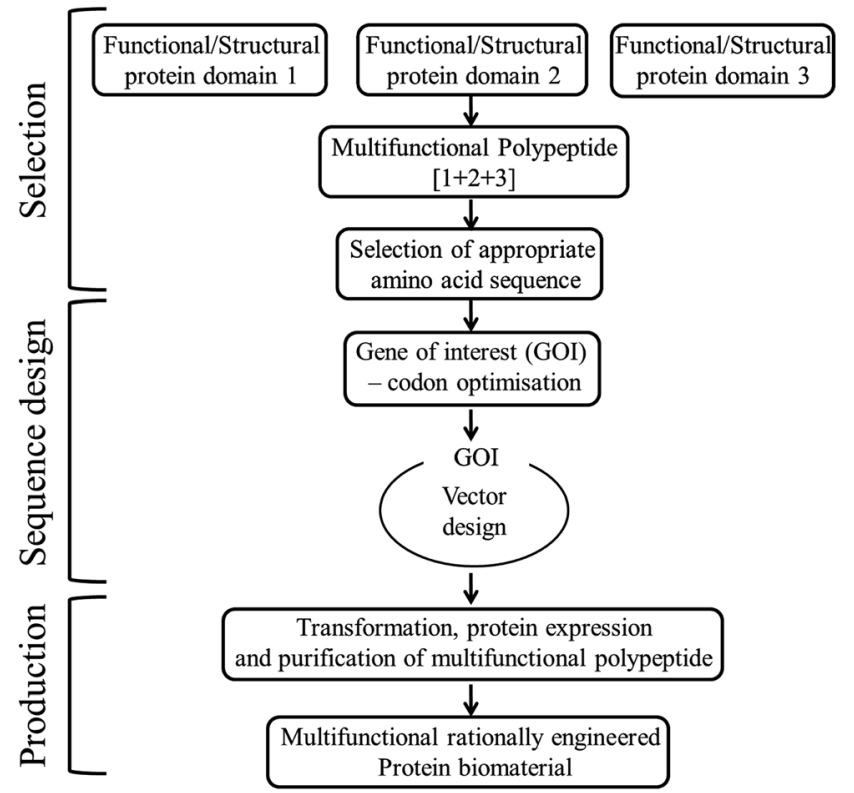

Fig. 3 Steps involved in the rational design of multifunctional modular protein engineered biomaterial construction. 
compound curcumin serves as an excellent wound healing biomaterial. ${ }^{61}$ Wound healing by collagen, chitosan or silk proteins sericin/fibroin have also been enhanced by incorporating anti-inflammatories, antiseptics, antibiotics, nanoparticles and other bioactive agents. ${ }^{\mathbf{6 2 , 6 3}}$ Use of plasma modified collagen is yet another new approach towards wound healing ${ }^{\mathbf{6 4}}$ mainly in diabetic and immuno-compromised patients. Plasma treatment along with collagen component was reported to enhance the rate of angiogenesis and the wound healing process.

Biological adhesives/sealants. Biological or tissue adhesives/ sealants have several potential medical applications that include topical wound closure, replacement of sutures or staples in internal surgical procedures, adhesion of dental/ corneal onlays or inlays and to prevent post-surgical adhesions. Tissue adhesive made up of albumin or gelatin is the commonly available protein based adhesives with less toxicity and high mechanical strength. Gelatin is a hydrolyzed form of collagen which is a fibrous insoluble protein found in bone, skin and connective tissues. Highly porous alkaline treated gelatin adhesives exhibits good cell adhesion as well as angiogenesis. ${ }^{65}$ Similarly, a novel tissue adhesive named "BCD" was developed from, bovine serum albumin (BSA), citrate acid (CA) and dopamine ${ }^{66}$ which exhibited 10 times better adhesion stress than the commercially existing fibrin glue within a time span of 30 minutes. Membranes made up of chitin and chitosan polysaccharides also serve as biological adhesives. ${ }^{67,68}$

Biodegradable Sutures. Suture materials are the mostly used biomaterials during a surgery to help the wound healing process by sealing the wounded area. The suture material should ideally be biocompatibile with appropriate physical strength. They can be either absorbable or non-absorbable sutures. Biodegradable/ absorbable sutures are more preferred as it is not necessary to remove the suture material. Silk has been used as medical suture material since a long time, but the silk fibroin present in it is reported to undergo a very slow degradation in human body by proteolysis. ${ }^{69}$ Recent findings have proved that incorporation of an antiseptic, 4-hexylresorcinol, in silk sutures exhibited antimicrobial as well as biodegradable properties comparable to a commercial bioresorbable suture, polyglactin 910 sutures. It also enhances the expression of metalloproteinases (MMP-2, -3, and -9) in macrophages that are responsible for the degradation of a wide range of proteins. Apart from these, biodegradable metal $^{49}$ and biopolymeric sutures ${ }^{50}$ are also exploited for soft and hard tissue sutures. It is interesting to note the development of a regenerative biomedical device where an in situ photochemical deposition technology is used to deposit silver on an absorbable co-polymer, poly(lactic-co-glycolic acid) sutures, functionalized with silk sericin. ${ }^{48}$

Carriers in drug delivery systems. Drug delivery systems are used to overcome the critical issues of drug insolubility, instability in normal physiological environments, poor uptake/ selectivity for target cells/tissues and other side effects. Among the protein based drug delivery systems, the ones prepared from albumin of serum or chicken eggs is the mainly explored protein for developing nanostructures of protein based drug delivery systems. ${ }^{.1,70}$ Albumin possesses the advantages of natural origin, ability to solubilize wide range of binding sites that can be exploited for drug delivery. Naturally occurring plant proteins $^{52}$ such as, zein from maize, gliadin from wheat and corn, legumin from leguminous seeds and lectins binding selectively to carbohydrate residues, are formulated into nanoparticles and used in drug delivery. These have been reported to exhibit biocompatibility, increased solubility, prolonged drug release, reduction in toxicity and side effects of the drugs. In addition to all these drug delivery systems, chitosan, ${ }^{53}$ polymer $^{54}$ and inorganic bioceramic ${ }^{55}$ based drug delivery systems, usually in the form of nanoparticles or carriers also exists to deliver antibiotics/specific drugs to the surgical site or tumors for cancer treatment. $^{71}$

Biosensor materials. Conducting polymers have drawn keen interest of researchers to explore their use in biomedical applications like drug delivery systems, biomedical implants, tissue engineering and biosensors. These conducting polymers possess optical and electrical properties like those of semiconductors and metals, and are also easy to synthesize $e^{72-74}$ by electrochemical or chemical methods. ${ }^{75,76}$ Synthetic nerve conduits have been fabricated from the blends of polypyrrole and poly(D,L-)lactic acid ${ }^{77}$ which has the potential to be used in nerve tissue regeneration. Polyaniline and its derivatives have also been studied for its biomedical applications including, neural probes, biosensors, controlled drug delivery, and tissue engineering applications. ${ }^{57,58}$ Recently, silicon nanowires have been used to detect electrical signals from viable cells, tissues and organs, which have the potential to be used as biosensors that monitor the ionic species traversing the cell membrane with the change in potential of the electric field. ${ }^{78}$ Further research and development of these materials are being investigated for clinical applications.

2.1.2 Rationally engineered functional domains for modular protein materials. Tissue engineering basically involves two principal approaches for replacement of tissues, one is by in vitro culturing of cells on biodegradable scaffolds and the second is by in situ tissue regeneration by ingrowth of cells on acellular matrices. To achieve this goal of cellular interactions, certain growth factors in soluble form or adhesive proteins bound to matrix are employed for growth of preferred cells. Some selected peptide domains including growth factors, structural domains and peptide domains of cell adhesion are given in the Table 2 along with their respective functionalities and selective references for understanding each in detail. These well characterized peptide domains can be rationally arranged, crosslinked into polypeptides, ultimately resulting in biomaterials, according to the needs or their end applications.

The laminin derived peptides such as YIGSR, CDPGYIGSR, IKVAV, etc., were reported to adhere nerve cells selectively ${ }^{79}$ and a fibronectin derived peptide KQAGDV shows specific $\alpha 5 \beta 1$ integrin mediated cell behavior. The stromal cells and growth factors from patient's blood, including platelet rich plasma and platelet rich fibrin preparations, have been tested and are in clinical use for wound healing and tissue regeneration. ${ }^{\mathbf{4 0 , 4 1}}$ These preparations can be made personalized to the specific needs of the patients where the growth factors are 
Table 2 List of common functional domains in use for rational designing of modular protein engineered materials along with domain functionality and selective references

\begin{tabular}{|c|c|c|}
\hline Peptides: & Cell adhesion: & \\
\hline RGD, REDV, LDV peptides & $\begin{array}{l}\text { - Promotes attachment of cells by interaction } \\
\text { with integrin receptors and selective to cell lines }\end{array}$ & 89,79 and 90 \\
\hline $\begin{array}{l}\text { YIGSR, CDPGYIGSR, IKVAV, RNIAEIIKDI, } \\
\text { YFQRYLI, PDSGR- laminin derived peptides }\end{array}$ & $\begin{array}{l}\text { - Laminin derived peptides selectively for nerve } \\
\text { cell adhesion }\end{array}$ & $91-96$ \\
\hline KQAGDV- peptide from fibronectin & $\begin{array}{l}\text { - Elicits certain specific } \alpha 5 \beta 1 \text { integrin mediated } \\
\text { cell behavior }\end{array}$ & 97 \\
\hline $\begin{array}{l}\text { Platelet-derived growth factor (PDGF) - homo- } \\
\text { (PDGF-AA, PDGF-BB, PDGF-CC, and PDGF-DD) } \\
\text { and heterodimeric (PDGF-AB) polypeptide } \\
\text { dimers }\end{array}$ & $\begin{array}{l}\text { - Wound healing of hard and soft tissues, re- } \\
\text { epithelialization, central nervous system (CNS) } \\
\text { development and also angiogenesis in some } \\
\text { tissues }\end{array}$ & 80,85 and 98 \\
\hline $\begin{array}{l}\text { Vascular Endothelium Growth factor (VEGF) - } \\
\text { VEGF-A, -B, -C, -D, and -E - VEGF-A }\end{array}$ & $\begin{array}{l}\text { - For nerve repair and treatment of } \\
\text { neurodegenerative conditions by stimulating } \\
\text { neurogenesis and neuroprotection } \\
\text { - Promotes vasculogenesis and angiogenesis by } \\
\text { stimulation of endothelial cell migration and } \\
\text { proliferation. }\end{array}$ & 84,85 and 99 \\
\hline $\begin{array}{l}\text { Transforming Growth factor (TGF)- } \beta \text { : TGF- } \beta 1 \text { - } \\
\text { predominant isoform bone morphogenetic } \\
\text { proteins (BMPs)-TGF subfamily(Platelets - } \\
\text { major source of TGF- } \beta \text { ) }\end{array}$ & $\begin{array}{l}\text { - Wound healing, angiogenesis, } \\
\text { reepithelialization, and connective tissue } \\
\text { generation } \\
\text { - ECM synthesis and reinforcement, bone } \\
\text { formation, healing and osteoblast deposition on } \\
\text { the collagen matrix of bone }\end{array}$ & 85 and 98 \\
\hline $\begin{array}{l}\text { Structural domain: } \\
\text { Flastin like polvpeptides (VPGXG) }\end{array}$ & Thermo-responsive and mechanical properties & 86 \\
\hline Elastin like polypeptides (VPGXG) $n$ & like native elastin & \\
\hline $\begin{array}{l}\mathrm{X}=\text { any amino acid except proline } \\
\mathrm{X}=\text { lysine, allows crosslinking via primary } \\
\text { amine side chains }\end{array}$ & & 100 \\
\hline $\begin{array}{l}\mathrm{X}=\text { cysteine, allows surface immobilization and } \\
\text { crosslining }\end{array}$ & & 101 \\
\hline
\end{tabular}

released from these platelets and intracellular signaling pathways are activated for specific tissue formation/repair. The platelet growth factors including, homo- (PDGF-AA, PDGF$\mathrm{BB}$, PDGF-CC, and PDGF-DD) and heterodimeric (PDGF-AB) polypeptide dimers, have been reported to aid in wound healing by re-epithelialization. ${ }^{80}$ Further, human platelet lysates are used as supplements for stem cell therapy in order to retain its biological properties, reduce the culture time and promote regeneration of target tissue by growth and differentiation of cells. ${ }^{81,82}$ Whereas, Vascular endothelial growth factor A (VEGF-A), a member of cysteine knot family, is well known for its vital roles in blood vessel growth. In mammals, it also includes VEGF-B, VEGF-C, VEGF-D and placental growth factor (PlGF, or PGF), as inducer of blood vessel development. ${ }^{83}$ These have also been reported to be involved in neuron generation. ${ }^{84}$ Transforming growth factor (TGF)- $\beta$ are mostly found in platelets, aiding in inflammation, re-epithelialisation, matrix formation and remodeling. ${ }^{85}$ Apart from these growth factors, there are structural protein domains like, elastin like polypeptides ${ }^{86}$ and resilin like polypeptides, ${ }^{87}$ which have been crosslinked by different methods ${ }^{88}$ to enhance the mechanical, elastic or resilience properties forming hydrogels or other biomaterials.

Another significant rational design from protein domains includes, a hybrid of mechanically strong GB1(B1 immunoglobulin binding domain of streptococcal protein G) protein domain ${ }^{102}$ and highly elastic resilin protein domain which were integrated by recombinant techniques to obtain artificial elastomeric proteins. ${ }^{103}$ The tandem repeats of GB1 and resilin were then photochemically crosslinked ${ }^{104}$ in different random combinations, $(\mathrm{GR})_{4}, \mathrm{GRG}_{5} \mathrm{RG}_{4} \mathrm{R}, \mathrm{GRG}_{5} \mathrm{R}, \mathrm{GRG}_{9} \mathrm{R}, \mathrm{G}_{8}$, that resulted in biomaterials that were hydrated and mimicked elastic properties of muscles as illustrated in Fig. 4. Each of the randomly combined ensembles were reported to possess varied mechanical properties, with two of the hydrogels formed by ensembles $(\mathrm{GR})_{4}$ and $\mathrm{GRG}_{5} \mathrm{RG}_{4} \mathrm{R}$ possessing equivalent mechanical properties, to that of the muscle proteins in humans, and could potentially be used as scaffolds/matrices for tissue engineering of muscles. Rational design of protein biomaterials can thus be constructed without much complications, with the only limitation being the need for prior knowledge about structural data of the parent proteins. 


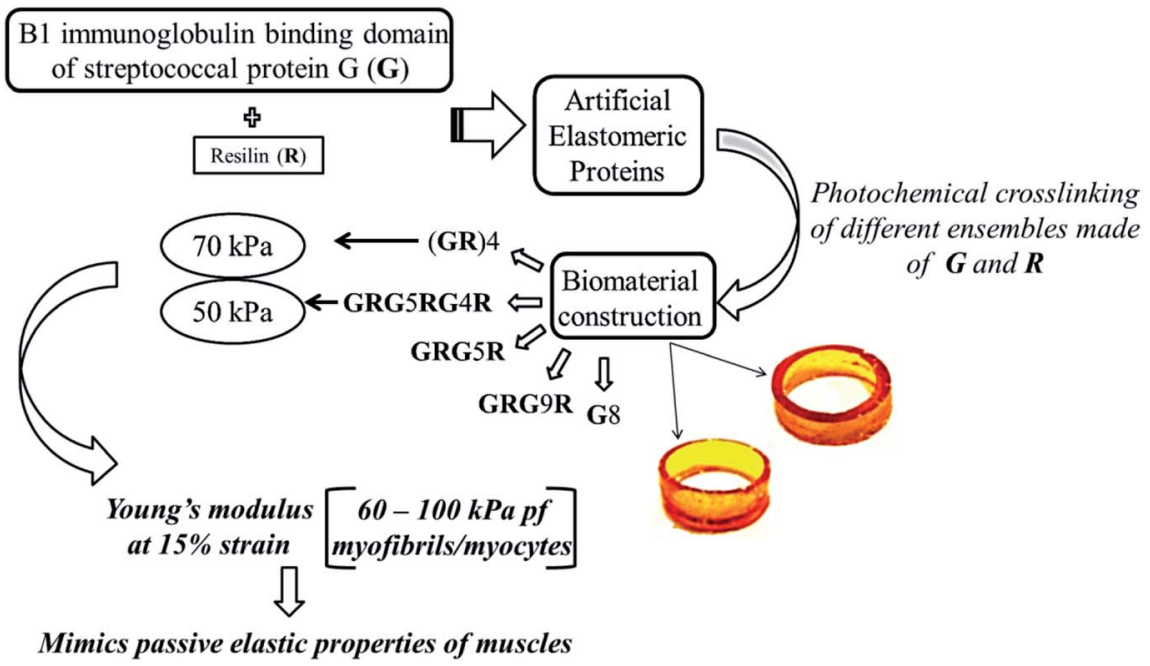

Fig. 4 Schematics depicting the bottom up approach to generate macroscopic protein biomaterials following rational design strategy.

2.1.3 Rationally engineered protein materials for specific tissue regeneration

Scaffold biomaterials for tissue regeneration. As collagen fibers have strength, flexibility, and the ability to be oriented and woven, they are used as scaffolds in skin repair, ${ }^{\mathbf{1 0 5}, 106}$ engineering vascular grafts, ${ }^{\mathbf{1 0 7}}$ bone repair ${ }^{\mathbf{1 0 8}}$ and also as carriers in drug delivery systems ${ }^{109}$ and wound healing. ${ }^{110}$ Though collagen finds various applications it lacks mechanical strength and control of degradation rate, hence collagen are combined with other synthetic or natural biomaterials to overcome these limitations. In recent days, microporous electro spun scaffolds with nano fiber mesh composed of collagen type I and synthetic polymer, polycaprolactone, are used for skin repair and regeneration. ${ }^{111}$ Silk is also a structured fibrous protein known for its mechanical strength and self-assembling ability that can form fibers. ${ }^{112}$ These silk fibers are formed by insects like silkworm and spiders for its cocoon and nest construction. ${ }^{113}$ Silk fibroin offers significant mechanical strength, degradability and biocompatibility, forming highly loaded grafts that fits for musculoskeletal tissue engineering. ${ }^{\mathbf{1 1 4 , 1 1 5}}$ Keratins formed by $\alpha$ helical coiled coil dimers, are structural proteins present in the epidermis appendages like nails, wool, hair and in the cytoskeletons of epithelial cells. ${ }^{116,117}$ These are biocompatible and are cell adhesive due to the presence of cell binding domain (LDV or Leu-Asp-Val), which makes it suitable for preparation of scaffolds for tissue engineering. ${ }^{\mathbf{1 1 8 , 1 1 9}}$ Nerve regeneration using keratin hydrogel scaffolds have also been developed and patented. ${ }^{\mathbf{1 2 0}}$ Further, primary evidence is available for the application of keratin biomaterial in providing protective effect or treatment, for the cells in hypoxia or low oxygen levels, which also helps in inducing cardiac regeneration after myocardial infarction. ${ }^{\mathbf{1 2 1}}$ The bioresorbable calcium phosphate ceramics are found to be a remarkable scaffold material for the regeneration of bone due to its ability to stimulate osteogenesis. ${ }^{\mathbf{1 2 2}}$ Based on the calcium and phosphate ratio, crystalline phase and crystallinity of calcium phosphate ceramics, release of calcium and phosphate ions and mineralization of bone occurs. ${ }^{\mathbf{1 2 3 , 1 2 4}}$ This unique property separates them from other types of ceramics used in bones like alumina or zirconia which are biologically inert. In this regard, alumina and zirconia are used together as composites $\mathbf{s 2 5 , 1 2 6}^{\mathbf{1 2 5}}$ or with bioactive agents or polymers. Calcium phosphate based composites with natural polymers like apatite-collagen, apatite-cellulose, octa calcium phosphate-collagen ${ }^{\mathbf{1 2 7}, \mathbf{1 2 8}}$ have been reported to mimic the mechanical properties of bones, for their use in bone tissue engineering. Several biological molecules like bone morphogenetic proteins, laminin, heparin have been incorporated into the apatite layer, ${ }^{\mathbf{1 2 9 , 1 3 0}}$ allowing further addition of active agents and extending the application of these composites in drug delivery systems. ${ }^{\mathbf{1 3 1}}$ Electro spun nano-fibre scaffolds or films from a combination of well-known proteins like collagen, silk fibroin and a synthetic polymer polycaprolactone not only adds to mechanical strength, but have also been proven as appropriate scaffold for tissue engineering urethral reconstruction. ${ }^{\mathbf{1 3 2}}$ Biocompatibility and conductivity for cell proliferation were proved to be feasible with the rationally designed composite films of collagen protein with nano fibres of a conducting polymer, polyaniline. ${ }^{\mathbf{1 3 3}}$ Polyanilines have also been studied for its use as biosensor materials, due to its electrical conductivity and biocompatibility when combined with natural proteins like collagen. ${ }^{57,58}$ For further reading about tissue engineering applications and their respective base biomaterials, selective references listed in the Table 3 can be referred.

Thermo-responsive biomaterial. Elastin-like polypeptides (ELPs) are chosen as a representative to explain the rational design of protein with temperature induced responses for biomedical application. ELPs are artificial proteins obtained from the natural protein elastin, major component of vascular wall, with repeating VPGXG amino acid sequences. These proteins exhibit an inverse phase transition at a specific temperature at which they are in soluble aqueous form, precipitates when raised to a gelatinous aggregate called a coacervate. ${ }^{\mathbf{1 3 4 , 1 3 5}}$ Urry et al. ${ }^{\mathbf{1 3 6}}$ reported that the temperature for the transition of polypeptide depends on mean residue hydrophobicity. Based on these results from Urry et al., 
Table 3 Scaffold materials for tissue engineering

\begin{tabular}{lll}
\hline Tissue Engineering Applications & Source of scaffold materials \\
\hline Bone repair & $\begin{array}{l}\text { Collagen calcium phosphate, hydroxyapatite } \\
\text { ceramics } \\
\text { Type I collagen, keratin, hyaluronic acid } \\
\text { derivatives, polyglycolic acid (neurotube), } \\
\text { polycaprolactone (neuroLac) }\end{array}$ \\
& $\begin{array}{l}\text { Collagen and chitosan, polycaprolactone (PCL), } \\
\text { and poly-ethylene-glycol (PEG), gelatin/poly } \\
\text { (vinyl alcohol) (Gel/PVA) }\end{array}$ \\
Skin repair/regeneration & $\begin{array}{l}\text { Poly(L-lactic acid) (PLLA) and segmented } \\
\text { polyurethane (PHD) with surface modified } \\
\text { heparin, polycaprolactone and collagen }\end{array}$ \\
Dascular grafts & $\begin{array}{l}\text { Decellularized cartilage, devitalized cartilage } \\
\text { Silk, collagen }\end{array}$ &
\end{tabular}

incorporation of valine, glycine and alanine in a $5: 3: 2$ ratio, respectively, at the guest position $\mathrm{X}$ of the residue VPG-X-G, a ten pentapeptide sequence was genetically engineered. It was reported $^{137}$ that the liquid like property of these ELPs below the transition temperature, makes it suitable for mixing cells and cell seeding, while the gel coacervate formed above the transition temperature, exhibits three times increase in complex shear modulus and comparable mechanical properties to that of hyaluronan and collagen, the extracellular matrix proteins. In addition these ELPs also maintains histological appearance, cell viability and chondrocyte phenotype in cell culture studies, proving its potential use as scaffolds for cartilaginous tissue repair.

\subsection{Protein engineering strategies via directed evolution}

Directed evolution guides the scientists to evolve RNA, proteins, metabolic pathways, genetic circuits and also whole cells in a repetitive manner to obtain properties that are not conferred by nature. Directed evolution of proteins is usually carried out to obtain proteins with new or enhanced properties. It enables us to exploit a protein or enzyme that can confer desired properties for their applications in pharmaceutical or chemical industries. The strategy of protein design typically involves four main steps,

(i) Identification of appropriate parent sequences

(ii) Mutation of parent sequences by one of the different methodologies to generate mutant libraries

(iii) Screening of the library for enhanced or desirable function/property

(iv) Repeating the mutational process to obtain variants with improved/desired properties

Diverse libraries are generally created by mutagenesis or recombination, though many other methodologies are being created from time to time. In the same way, high throughput screening techniques are being developed to reduce the experimental loads in finding variants with desired properties. ${ }^{\mathbf{1 5 0 - 1 5 2}}$ Despite incomplete knowledge about protein folding, structure, expression and the mechanism of action of enzymes, directed evolution can be employed to enhance the inherent properties of enzymes. ${ }^{153}$ It includes enzyme activity, selectivity, substrate scope or stability for the application in preparation of pharmacological intermediates or fine industrial chemicals. ${ }^{154}$ The most common methods of gene mutagenesis includes, error prone PCR, saturation mutagenesis and DNA shuffling. Few of the notable strategies and examples are discussed as follows.

- Directed evolution approaches like error prone PCR, ${ }^{155}$ gene shuffling, ${ }^{156}$ site saturation mutagenesis along with appropriate screening steps, enhancement of thermostability in enzymes like laccases, cellobiohydrolases, $\alpha$-amylase ${ }^{157}$ has been made possible. Directed evolution have always had the problem of screening of large number of resulting variants. Cornvik and his group had made efforts to make screening simpler by developing a new screening method for thermostability of engineered proteins, known as the HotCoFi method. ${ }^{158}$ This method is based on colony filtration (CoFi) blot and incubation of the expressed colonies at wide range of temperatures, where the proteins unfold and aggregate, the filter membrane retains the aggregates and allows the soluble proteins to pass on to a nitrocellulose membrane. It is followed by detection with affinity reagents against the target or with the help of tags fused to targets, where high signal corresponds to soluble proteins and the loss in signal corresponds to aggregated or unfolded proteins.

- Computational modeling has been combined with directed evolution approaches, to design a transaminase with desirable activity for amination of prositagliptin ketone. Synthesis of an antidiabetic drug, sitagliptin ${ }^{\mathbf{1 5 9}}$ has been made possible by the directed evolution of a transaminase, as biocatalyst for chiral amine synthesis. In silico methods were integrated with directed evolution, more like a semi-rational approach in cases where well annotated structural data are missing for the protein of interest.

- Attempts using directed evolution based recombination or shuffling of secondary structures of the two homologous proteins, immunoglobulin domain 27 of titin (I27) and immunoglobulin domain 32 of titin (I32) to develop new mechanical proteins $^{\mathbf{1 6 0}}$ is illustrated in Fig. 5. Single molecule atomic force microscopy studies were carried out with tandem repeats ${ }^{\mathbf{1 6 1}}$ of a well characterized protein GB1 (B1 immunoglobulin binding domain of streptococcal protein G) with contour length of 18 
$\mathrm{nm}^{162,163}$ and the hybrids (i.e. [GB1-hybrid] $]_{4}$ ), to probe their unfolding events as shown as force-extension curves in Fig. 6. ${ }^{\mathbf{1 6 0}}$ Six out of 13 daughter protein hybrids were found to be mechanically stable with contour length of $28 \mathrm{~nm}$ as depicted in Fig. 6(a), similar to that of the wild type parent proteins I27 and I32. ${ }^{164}$ Whereas, three protein hybrids were categorized to possess dual personality (Fig. 6(b)), with two kinds of mechanical stabilities with unfolding events similar to parent proteins as well as unfolding at forces of undetectable limits. Also, four of the hybrids were found to be mechanically labile Fig. 6(c), with no unfolding events of Ig domain of contour length $28 \mathrm{~nm}$. This study enlightens the importance of adjacent residues of secondary structures as well as the non-local bindings, in protein folding. It was suggested that computational methods like SCHEMA ${ }^{\mathbf{1 6 5 , 1 6 6}}$ could be used for increasing the success rate while designing proteins by using DNA shuffling based recombination approaches. SCHEMA, ${ }^{\mathbf{1 6 6}}$ involves prediction of fragments of homologous proteins that can be recombined without disturbing the structural integrity of proteins. This computational tool finds compact polypeptides with large number of intra-block interactions that corresponds to fragments that can be swapped while preserving the structure. The resulting fragments or schemata could be then recombined by laboratory based recombination methods.

2.2.1 Constitution of biomaterials with proteins evolved via directed evolution. Similar to the above strategies, the proteins that have evolved using directed evolution approaches can be crosslinked and fabricated into any form of biomaterials including hydrogels, according to their properties. Though there are no existing literatures on directed evolution based protein biomaterials, attempts have been made in creating protein variants by adopting directed evolution approaches. As mentioned before in this review under the sub-section directed evolution based protein design, several hybrid proteins have been obtained by directed evolution of immunoglobulin domain 27 of titin (I27) and immunoglobulin domain 32 of titin $(\mathrm{I} 32)^{\mathbf{1 6 0}}$ as shown in Fig. 3. Few hybrids were found to be mechanically stable and were considered for photocrosslinking or other crosslinking techniques for construction of protein biomaterials. Such directed evolution based protein biomaterials can be generated with ease, if limitations in the screening of evolved protein variants are eliminated with easy effective screening techniques. This proposed strategy of directed evolution based protein biomaterial generation is represented in the Fig. 7.

2.2.2 Machine learning-assisted protein evolution. Machine learning is a subfield of artificial intelligence that has enhanced the role of computers in scientific research. Machine learning applications depend primarily on statistical algorithms and serves as tools to generate, test and refine scientific models for better performance. These techniques deal with complex problems with larger combinatorial spaces

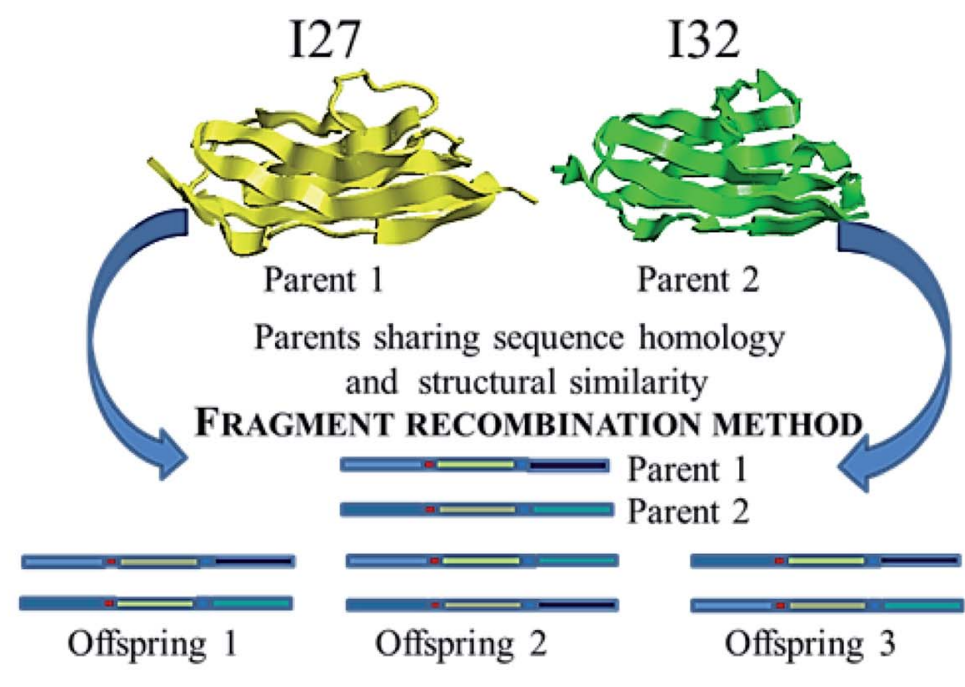

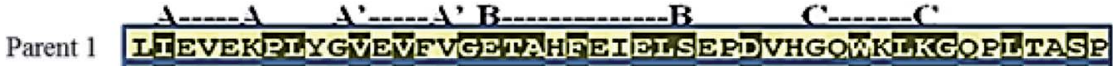

Parent 2 VIGILREIKDVTVTAGETATEDOELSYEDIPVEWYIKGKKLEPSD

D-_._. DE

Parent 1 DCEIIEDGKKHIII IHNCQLGMTGEVSEOAANAKSAANLKVKLEL

Parent 2 KVVPRSEGKVHTLTLRDVKLEDAGEVQITAKDFKTHANLFVKDP

Construction of hybrid proteins with varying mechanical properties

- by swapping secondary structures between parent 1 and parent 2

Fig. 5 Schematics showing the method of fragment recombination used to construct hybrid proteins from the two distantly related or nonrelated parent proteins 1 and 2 . 

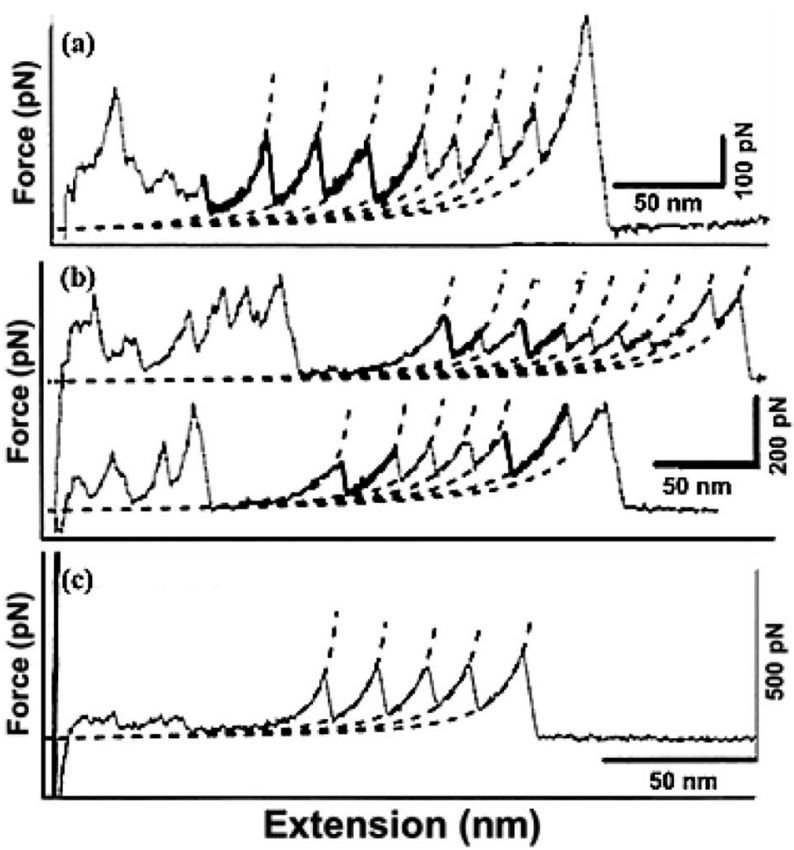

Fig. 6 Illustration on the variation in mechanical properties upon protein recombination. Three different kinds of unfolding events: (a) stable, (b) dual, (c) labile from the hybrids with tandem repeats of immunoglobulin like domains (hybrids) and B1 domain of Protein G (GB1-hybrid $)_{4}$ displaying multiple contour lengths. The thick lines in the force extension curve depict the unfolding event of the hybrids while the normal lines represent for GB1.

or nonlinear processes, that cannot be handled by conventional methods or can be dealt with only at a huge computational cost. ${ }^{167}$ This machine learning technique could be applied for evolving countless proteins available in nature with varied potentials for various applications. Machine learning works by collection of data which are then represented suitably, followed by choosing an appropriate model to represent it. These models are known to be trained using the existing or training data.
In case of the contemporary directed evolution, several variants are generated from parental sequences, screened for preferred properties, and then the best variants are selected to act as parents for the next round of mutation/evolution, discarding other variants. When machine learning technique is applied in evolving a protein of interest, the sequences and screening data of all the variants can be exploited to train a set of models including linear, kernel, neural network, and ensemble methods. The model exhibiting highest accuracy is then employed for screening of the variants in a round of in silico evolution, in which models simulate the variant sequences for fitness and rank them accordingly. This results in a restricted library of variants with the highest simulated fitness which are then generated and screened experimentally. ${ }^{168}$ The best variant from these restricted libraries are then chosen as parent sequence for the next round of evolution with mutations at new positions, followed by identification of further improvised variants. Thereby the in silico screening using sequencefitness relationship in machine learning investigates the entire combinatorial space of mutations at multiple positions. More recently, the advantages of in silico screening by means of machine learning technique was examined and proved to be rapid, ${ }^{169}$ using the dataset collected by $\mathrm{Wu}$ and coworkers, ${ }^{\mathbf{1 7 0}}$ who reported the effects of mutations at four positions in human GB1 binding protein on antibody binding. Protein engineering applications of machine learning have identified favorable mutations ${ }^{\mathbf{1 7 1}}$ and best possible combinations of protein fragments ${ }^{\mathbf{1 7 2}}$ for enhanced enzyme activity and protein stability. ${ }^{173}$

\section{Future scope}

The strategy of directed evolution has been found to be simpler than the traditional rational method to successfully design/ engineer novel proteins with desired properties, despite of insufficient knowledge about existing parent proteins. Though several methodologies do exist in directed evolution approach, easy, rapid, sensitive and affordable screening techniques are yet to be established for identifying the variants with enhanced

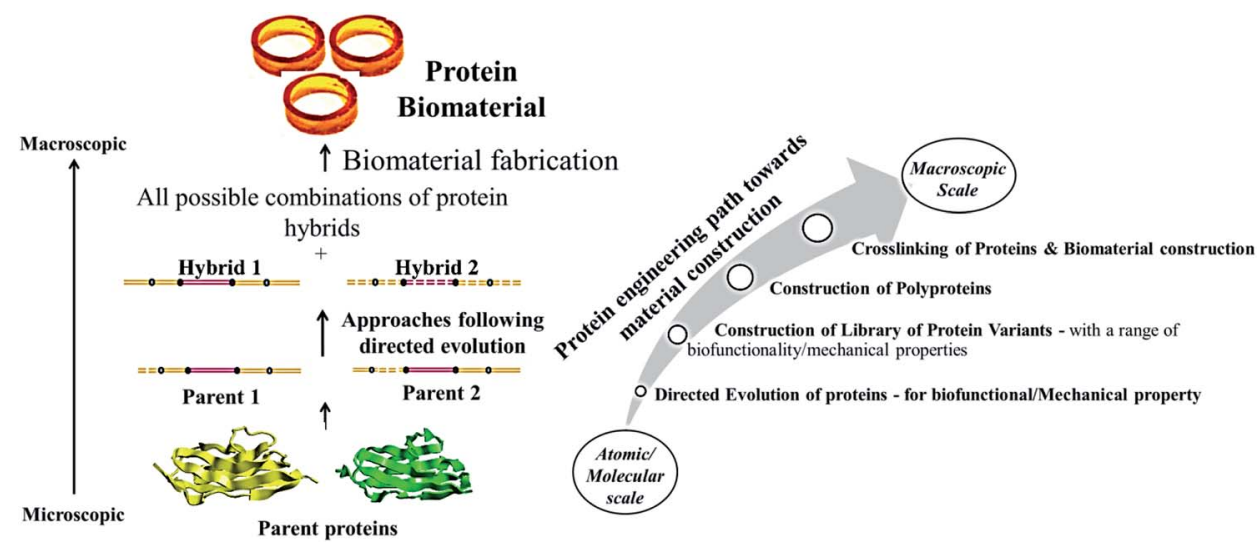

Fig. 7 Schematic representing the construction of biomaterials from the proteins evolved through directed evolution (Left). The various steps involved and the variation in properties as we move from microscopic (single molecule/ensemble level to macroscopic biomaterials is also shown (Right). 
desirable traits. Proteins or enzymes obtained by directed evolution have found a firm place in industrial and therapeutic applications, and are still striving for improvement in other biomedical fields of applications. In the same way proteins are to be mainly engineered considering their biofunctional and mechanical properties by rational design or directed evolution in creating a library of desirable variants, and crosslink them to form macroscopic potential biomaterials as illustrated in Fig. 6 . This can be anticipated to broaden the toolbox of engineered proteins for their application as biomaterials. Protein biomaterials are known for their biocompatibility, inherent biofunctionality and biodegradability, making them more suitable as scaffold materials for tissue engineering. Combinations of synthetic polymers, ceramics and also various functional/ structural peptide domains along with the natural/engineered proteins as base biomaterials are to be explored more to make them fit for suitable biomedical applications. Also, it is necessary to prevent non-specific protein adsorption on the surface of these protein biomaterials that elicits several biological responses. Though polymer coatings are available to protect the biomaterials from non-specific adsorption, further research is required to develop more stable, bioinert and biospecific polymer coatings that lasts for a longer time on biomaterial surfaces under physiological conditions.

\section{Conflicts of interest}

We have declared no conflict of interest.

\section{Acknowledgements}

The authors are thankful to Vellore Institute of Technology, India for their support and encouragement in preparing this review. We also thank DST SERB for their financial support (DST Project id: YSS/2014/00296) to perform experiments for preliminary investigations.

\section{References}

1 R. V. Ulijn, N. Bibi, V. Jayawarna, P. D. Thornton, S. J. Todd, R. J. Mart, A. M. Smith and J. E. Gough, Mater. Today, 2007, 10, 40-48.

2 L. T. Saldin, M. C. Cramer, S. S. Velankar, L. J. White and S. F. Badylak, Acta Biomater., 2017, 49, 1-15.

3 N. E. Fedorovich, J. Alblas, J. R. de Wijn, W. E. Hennink, A. J. Verbout and W. J. Dhert, Tissue Eng., 2007, 13, 19051925.

4 M. C. Cushing and K. S. Anseth, Science, 2007, 316, 11331134.

5 F. J. O'brien, Mater. Today, 2011, 14, 88-95.

6 D. F. Williams and J. Cunningham, Materials in clinical dentistry, Oxford University Press, USA, 1979.

7 C. W. Hall, J. Biomed. Mater. Res., 1971, 5, 1-4.

8 J. Lister, Br. Med. J., 1967, 2, 9-12.

9 P. I. Branemark, J. Prosthet. Dent., 1983, 50, 399-410.

10 R. Toita, K. Tsuru and K. Ishikawa, Mater. Sci. Eng. C, 2016, 68, 291-298.
11 Q. Chen and G. A. Thouas, Mater. Sci. Eng. R Rep., 2015, 87, 1-57.

12 B. Altmann, R.-J. Kohal, T. Steinberg, P. Tomakidi, M. Bächle-Haas, A. Wennerberg and W. Att, Tissue Eng., Part C, 2013, 19, 850-863.

13 W. She, N. Li, K. Luo, C. Guo, G. Wang, Y. Geng and Z. Gu, Biomaterials, 2013, 34, 2252-2264.

14 Y. Zhang, H. F. Chan and K. W. Leong, Adv. Drug Deliv. Rev., 2013, 65, 104-120.

15 J. Lam, E. C. Clark, E. L. Fong, E. J. Lee, S. Lu, Y. Tabata and A. G. Mikos, Biomaterials, 2016, 83, 332-346.

16 T. H. Qazi, D. J. Mooney, M. Pumberger, S. Geissler and G. N. Duda, Biomaterials, 2015, 53, 502-521.

17 L. Germain, P. De Berdt, J. Vanacker, J. Leprince, A. Diogenes, D. Jacobs, G. Vandermeulen, C. Bouzin, V. Preat, C. Dupont-Gillain and A. des Rieux, Regen. Med., 2015, 10, 153-167.

18 P. Whiting, J. Kerby, P. Coffey, L. da Cruz and R. McKernan, Phil. Trans. R. Soc. Lond. Ser. B Biol. Sci., 2015, 370, 20140375.

19 L. L. Hench, Science, 1980, 208, 826-831.

20 J.-A. Yang, J. Yeom, B. W. Hwang, A. S. Hoffman and S. K. Hahn, Prog. Polym. Sci., 2014, 39, 1973-1986.

$21 \mathrm{X} . \mathrm{Xu}, \mathrm{Z} . \mathrm{Xu}, \mathrm{X}$. Yang, Y. He and R. Lin, Int. J. Biol. Macromol., 2017, 95, 294-298.

22 K. M. Ulmer, Science, 1983, 219, 666-671.

23 M. N. Gupta, Eur. J. Biochem., 1992, 203, 25-32.

24 J. S. Richardson and D. C. Richardson, Trends Biochem. Sci., 1989, 14, 304-309.

25 B. Gutte, J. Biol. Chem., 1975, 250, 889-904.

26 F. Arnold, FASEB J., 1993, 7, 744-749.

27 B. I. Dahiyat and S. L. Mayo, Science, 1997, 278, 82-87.

28 M. V. Golynskiy and B. Seelig, Trends Biotechnol., 2010, 28, 340-345.

29 S. Lutz, Curr. Opin. Biotechnol., 2010, 21, 734-743.

30 R. A. Chica, N. Doucet and J. N. Pelletier, Curr. Opin. Biotechnol., 2005, 16, 378-384.

31 K. Steiner and H. Schwab, Comput. Struct. Biotechnol. J., 2012, 2, e201209010.

32 I. V. Korendovych, in Protein Eng., Springer, 2018, pp. 15-23.

33 M. Sobti and B. C. Mabbutt, in Protein Nanotechnology, Springer, 2013, pp. 233-250.

34 M. Lehmann and M. Wyss, Curr. Opin. Biotechnol., 2001, 12, 371-375.

35 W. Huang, A. Rollett and D. L. Kaplan, Expert Opin. Drug Deliv., 2015, 12, 779-791.

36 X. X. Xia, Q. Xu, X. Hu, G. Qin and D. L. Kaplan, Biomacromolecules, 2011, 12, 3844-3850.

37 R. L. DiMarco and S. C. Heilshorn, Adv. Mater., 2012, 24, 3923-3940.

38 N. H. Romano, D. Sengupta, C. Chung and S. C. Heilshorn, Biochim. Biophys. Acta, 2011, 1810, 339-349.

39 D. Archana, P. K. Dutta and J. Dutta, in Chitin and Chitosan for Regenerative Medicine, Springer, 2016, pp. 193-227.

40 E. Anitua, M. Sanchez, G. Orive and I. Andia, Biomaterials, 2007, 28, 4551-4560.

41 G. Intini, Biomaterials, 2009, 30, 4956-4966. 
42 S. Sapru, S. Das, M. Mandal, A. K. Ghosh and S. C. Kundu, Acta Biomater., 2018, 78, 137-150.

43 C. M. Elvin, T. Vuocolo, A. G. Brownlee, L. Sando, M. G. Huson, N. E. Liyou, P. R. Stockwell, R. E. Lyons, M. Kim, G. A. Edwards, G. Johnson, G. A. McFarland, J. A. Ramshaw and J. A. Werkmeister, Biomaterials, 2010, 31, 8323-8331.

44 S. P. Mandell and N. S. Gibran, Expert Opin. Biol. Ther., 2014, 14, 821-830.

45 G. Lee, C. K. Lee and M. Bynevelt, Spine, 2010, 35, E15221524.

46 T. W. Gilbert, S. F. Badylak, J. Gusenoff, E. J. Beckman, D. M. Clower, P. Daly and J. P. Rubin, Plast. Reconstr. Surg., 2008, 122, 95-102.

47 Y. Y. Jo, H. Kweon, D. W. Kim, M. K. Kim, S. G. Kim, J. Y. Kim, W. S. Chae, S. P. Hong, Y. H. Park, S. Y. Lee and J. Y. Choi, Sci. Rep., 2017, 7, 42441.

48 A. L. Gallo, M. Pollini and F. Paladini, J. Mater. Sci.: Mater. Med., 2018, 29, 133.

49 J. M. Seitz, M. Durisin, J. Goldman and J. W. Drelich, Adv. Healthcare Mater., 2015, 4, 1915-1936.

50 B. Joseph, A. George, S. Gopi, N. Kalarikkal and S. Thomas, Int. J. Pharm., 2017, 524, 454-466.

51 M. Karimi, S. Bahrami, S. B. Ravari, P. S. Zangabad, H. Mirshekari, M. Bozorgomid, S. Shahreza, M. Sori and M. R. Hamblin, Expert Opin. Drug Delivery, 2016, 13, 16091623.

52 H. Malekzad, H. Mirshekari, P. Sahandi Zangabad, S. Moosavi Basri, F. Baniasadi, M. Sharifi Aghdam, M. Karimi and M. R. Hamblin, Crit. Rev. Biotechnol., 2018, 38, 47-67.

53 A. Ali and S. Ahmed, Int. J. Biol. Macromol., 2018, 109, 273286.

54 F. Dilnawaz, Curr. Med. Chem., 2017, 24, 2423-2438.

55 S. Kumar Ts and K. Madhumathi, Ther. Deliv., 2016, 7, 573588.

56 M. Y. Truong, N. K. Dutta, N. R. Choudhury, M. Kim, C. M. Elvin, A. J. Hill, B. Thierry and K. Vasilev, Biomaterials, 2010, 31, 4434-4446.

57 L. Ghasemi-Mobarakeh, M. P. Prabhakaran, M. Morshed, M. H. Nasr-Esfahani, H. Baharvand, S. Kiani, S. S. AlDeyab and S. Ramakrishna, J. Tissue Eng. Regenerat. Med., 2011, 5, e17-35.

58 P. Humpolicek, V. Kasparkova, P. Saha and J. Stejskal, Synth. Met., 2012, 162, 722-727.

59 K. Las Heras, S. Santos-Vizcaino, A. Etxabide, J. Uranga, E. Santos-Vizcaino, P. Guerrero, J. Pedraz, M. Igartua, K. De La Caba and R. Hernandez, FarmaJournal, 2019, 4, 65.

60 J. Chu, P. Shi, W. Yan, J. Fu, Z. Yang, C. He, X. Deng and H. Liu, Nanoscale, 2018, 10, 9547-9560.

61 P. J. Manna, T. Mitra, N. Pramanik, V. Kavitha, A. Gnanamani and P. Kundu, Int. J. Biol. Macromol., 2015, 75, 437-446.

62 J. Liu, L. Yan, W. Yang, Y. Lan, Q. Zhu, H. Xu, C. Zheng and R. Guo, Bioactive Materials, 2019, 4, 151-159.

63 G. Tao, R. Cai, Y. Wang, L. Liu, H. Zuo, P. Zhao, A. Umar, C. Mao, Q. Xia and H. He, Mater. Des., 2019, 180, 107940.
64 L. O'Neill, P. Dobbyn, M. Kulkarni and A. Pandit, Clinical Plasma Medicine, 2018, 12, 23-32.

65 K. Yoshizawa, R. Mizuta and T. Taguchi, Biomaterials, 2015, 63, 14-23.

66 W. Zhu, Y. Peck, J. Iqbal and D.-A. Wang, Biomaterials, 2017, 147, 99-115.

67 A. Anitha, N. Deepa, K. Chennazhi, S. Nair, H. Tamura and R. Jayakumar, Carbohydr. Polym., 2011, 83, 66-73.

68 K. Azuma, M. Nishihara, H. Shimizu, Y. Itoh, O. Takashima, T. Osaki, N. Itoh, T. Imagawa, Y. Murahata, T. Tsuka, H. Izawa, S. Ifuku, S. Minami, H. Saimoto, Y. Okamoto and M. Morimoto, Biomaterials, 2015, 42, 20-29.

69 Y. Cao and B. Wang, Int. J. Mol. Sci., 2009, 10, 1514-1524.

70 R. C. Oppenheim, in Polymeric nanoparticles and microspheres, CRC Press, 2018, pp. 1-27.

71 J. Fan, S. Wang, W. Sun, S. Guo, Y. Kang, J. Du and X. Peng, AIChE J., 2018, 64, 835-859.

72 N. K. Guimard, N. Gomez and C. E. Schmidt, Prog. Polym. Sci., 2007, 32, 876-921.

73 B. Guo, L. Glavas and A.-C. Albertsson, Prog. Polym. Sci., 2013, 38, 1263-1286.

74 A. J. Heeger, Angew. Chem., Int. Ed., 2001, 40, 2591-2611.

75 A. Diaz, K. K. Kanazawa and G. P. Gardini, J. Chem. Soc., Chem. Commun., 1979, 635-636.

76 K. Kaneto, K. Yoshino and Y. Inuishi, Solid State Commun., 1983, 46, 389-391.

77 H. Xu, J. M. Holzwarth, Y. Yan, P. Xu, H. Zheng, Y. Yin, S. Li and P. X. Ma, Biomaterials, 2014, 35, 225-235.

78 X. Duan, R. Gao, P. Xie, T. Cohen-Karni, Q. Qing, H. S. Choe, B. Tian, X. Jiang and C. M. Lieber, Nat. Nanotechnol., 2012, 7, 174-179.

79 M. Fittkau, P. Zilla, D. Bezuidenhout, M. Lutolf, P. Human, J. A. Hubbell and N. Davies, Biomaterials, 2005, 26, 167-174.

80 J. Andrae, R. Gallini and C. Betsholtz, Genes Dev., 2008, 22, 1276-1312.

81 E. Anitua, R. Prado and G. Orive, Trends Biotechnol., 2013, 31, 364-374.

82 R. Crespo-Diaz, A. Behfar, G. W. Butler, D. J. Padley, M. G. Sarr, J. Bartunek, A. B. Dietz and A. Terzic, Cell Transplant., 2011, 20, 797-811.

83 T. Tammela, T. V. Petrova and K. Alitalo, Trends Cell Biol., 2005, 15, 434-441.

84 F. Mackenzie and C. Ruhrberg, Development, 2012, 139, 1371-1380.

85 S. Barrientos, O. Stojadinovic, M. S. Golinko, H. Brem and M. Tomic-Canic, Wound Repair Regen., 2008, 16, 585-601.

86 S. Roberts, M. Dzuricky and A. Chilkoti, FEBS Lett., 2015, 589, 2477-2486.

87 R. S.-C. Su, Y. Kim and J. C. Liu, Acta Biomater., 2014, 10, 1601-1611.

88 J. Brindha, K. Chanda and M. Balamurali, Mater. Sci. Eng. C, 2019, 95, 312.

89 S. L. Bellis, Biomaterials, 2011, 32, 4205-4210.

90 U. Hersel, C. Dahmen and H. Kessler, Biomaterials, 2003, 24, 4385-4415. 
91 J. P. Ranieri, R. Bellamkonda, E. J. Bekos, J. A. Gardella Jr, H. J. Mathieu, L. Ruiz and P. Aebischer, Int. J. Dev. Neurosci., 1994, 12, 725-735.

92 J. P. Ranieri, R. Bellamkonda, E. J. Bekos, T. G. Vargo, J. A. Gardella Jr and P. Aebischer, J. Biomed. Mater. Res., 1995, 29, 779-785.

93 L. Aucoin, C. Griffith, G. Pleizier, Y. Deslandes and H. Sheardown, J. Biomater. Sci., Polym. Ed., 2002, 13, 447462.

94 M. Huber, P. Heiduschka, S. Kienle, C. Pavlidis, J. Mack, T. Walk, G. Jung and S. Thanos, J. Biomed. Mater. Res., 1998, 41, 278-288.

95 J. C. Schense, J. Bloch, P. Aebischer and J. A. Hubbell, Nat. Biotechnol., 2000, 18, 415.

96 Y. W. Tong and M. S. Shoichet, J. Biomed. Mater. Res., 1998, 42, 85-95.

97 Y. Maeshima, U. L. Yerramalla, M. Dhanabal, K. A. Holthaus, S. Barbashov, S. Kharbanda, C. Reimer, M. Manfredi, W. M. Dickerson and R. Kalluri, J. Biol. Chem., 2001, 276, 31959-31968.

98 S. Graham, A. Leonidou, M. Lester, M. Heliotis, A. Mantalaris and E. Tsiridis, Expert Opin. Investig. Drugs, 2009, 18, 1633-1654.

99 C. Ruiz de Almodovar, D. Lambrechts, M. Mazzone and P. Carmeliet, Physiol. Rev., 2009, 89, 607-648.

100 H. Wang, L. Cai, A. Paul, A. Enejder and S. C. Heilshorn, Biomacromolecules, 2014, 15, 3421-3428.

101 Y. Yuan and P. Koria, J. Biomed. Mater. Res. A, 2016, 104, 697-706.

102 Y. Cao and H. Li, Nat. Mater., 2007, 6, 109-114.

103 S. Lv, D. M. Dudek, Y. Cao, M. M. Balamurali, J. Gosline and H. Li, Nature, 2010, 465, 69-73.

104 D. A. Fancy and T. Kodadek, Proc. Natl. Acad. Sci. U.S.A., 1999, 96, 6020-6024.

105 C. Helary, I. Bataille, A. Abed, C. Illoul, A. Anglo, L. Louedec, D. Letourneur, A. Meddahi-Pelle and M. M. Giraud-Guille, Biomaterials, 2010, 31, 481-490.

106 F. Wehrhan, E. Nkenke, I. Melnychenko, K. Amann, K. A. Schlegel, C. Goerlach, W. H. Zimmermann and S. Schultze-Mosgau, Dermatol. Surg., 2010, 36, 919-930.

107 I. S. Park, S. H. Kim, Y. H. Kim, I. H. Kim and S. H. Kim, J. Biomater. Sci. Polym. Ed., 2009, 20, 1645-1660.

108 F. G. Lyons, A. A. Al-Munajjed, S. M. Kieran, M. E. Toner, C. M. Murphy, G. P. Duffy and F. J. O'Brien, Biomaterials, 2010, 31, 9232-9243.

109 G. Kleinmann, S. Larson, B. Hunter, S. Stevens, N. Mamalis and R. J. Olson, Ophthalmologica, 2006, 221, 51-56.

110 M. Maeda, K. Kadota, M. Kajihara, A. Sano and K. Fujioka, J. Control. Release, 2001, 77, 261-272.

111 P. P. Bonvallet and S. L. Bellis, Microsc. Microanal., 2016, 22, 3.

112 M. Heim, L. Römer and T. Scheibel, Chem. Soc. Rev., 2010, 39, 156-164.

113 F. G. Omenetto and D. L. Kaplan, Science, 2010, 329, 528531.

114 T. Nau and A. Teuschl, World J. Orthop., 2015, 6, 127-136.
115 A. Teuschl, P. Heimel, S. Nurnberger, M. van Griensven, H. Redl and T. Nau, Am. J. Sports Med., 2016, 44, 1547-1557.

116 P. Hill, H. Brantley and M. Van Dyke, Biomaterials, 2010, 31, 585-593.

117 E. B. Lane and W. H. McLean, J. Pathol., 2004, 204, 355-366.

118 S. Reichl, Biomaterials, 2009, 30, 6854-6866.

119 A. Tachibana, S. Kaneko, T. Tanabe and K. Yamauchi, Biomaterials, 2005, 26, 297-302.

120 M. E. Van Dyke, US Pat., 8,968,764, 2015.

121 B. Lund, L. Burleson, M. James, S. Burris, P. Link and M. Brinkley, Keratin biomaterials attenuate hypoxia- $R$ mediated cell toxicity, Washington, 2015.

122 I. Denry and L. T. Kuhn, Dent. Mater., 2016, 32, 43-53.

123 S. V. Dorozhkin, Materials, 2013, 6, 3840-3942.

124 A. F. Khan, M. Saleem, A. Afzal, A. Ali, A. Khan and A. R. Khan, Mater. Sci. Eng. C, 2014, 35, 245-252.

125 H. C. Ko, J. S. Han, M. Bachle, J. H. Jang, S. W. Shin and D. J. Kim, Dent. Mater., 2007, 23, 1349-1355.

126 G. Schierano, F. Mussano, M. G. Faga, G. Menicucci, C. Manzella, C. Sabione, T. Genova, M. M. von Degerfeld, B. Peirone, A. Cassenti, P. Cassoni and S. Carossa, BioMed Res. Int., 2015, 2015, 157360.

127 A. Yoshida, T. Miyazaki, M. Ashizuka and E. Ishida, J. Biomater. Appl., 2006, 21, 179-194.

128 T. Kawai, K. Matsui, S. Iibuchi, T. Anada, Y. Honda, K. Sasaki, S. Kamakura, O. Suzuki and S. Echigo, Clin. Implant Dent. Relat. Res., 2011, 13, 112-123.

129 T. Kodama, T. Goto, T. Miyazaki and T. Takahashi, Int. J. Oral Maxillofac. Implant., 2008, 23, 1013-1019.

130 A. Oyane, M. Uchida and A. Ito, J. Biomed. Mater. Res. A, 2005, 72, 168-174.

131 T. Miyazaki, K. Ishikawa, Y. Shirosaki and C. Ohtsuki, Biol. Pharm. Bull., 2013, 36, 1670-1675.

132 G. Wei, C. Li, Q. Fu, Y. Xu and H. Li, Int. Urol. Nephrol., 2015, 47, 95-99.

133 H.-S. Kim, H. L. Hobbs, L. Wang, M. J. Rutten and C. C. Wamser, Synth. Met., 2009, 159, 1313-1318.

134 D. W. Urry, J. Protein Chem., 1988, 7, 1-34.

135 D. W. Urry, Prog. Biophys. Mol. Biol., 1992, 57, $23-57$.

136 D. W. Urry, C. H. Luan, T. M. Parker, D. C. Gowda, K. U. Prasad, M. C. Reid and A. Safavy, J. Am. Chem. Soc., 1991, 113, 4346-4348.

137 H. Betre, L. A. Setton, D. E. Meyer and A. Chilkoti, Biomacromolecules, 2002, 3, 910-916.

138 B. Fei, H. Xu, Y. Cao, S. Ma, H. Guo, T. Song, D. Qiao and Y. Cao, J. Ind. Microbiol. Biotechnol., 2013, 40, 457-464.

139 R. Boni, A. Ali, A. Shavandi and A. N. Clarkson, J. Biomed. Sci., 2018, 25, 90.

140 F. Mohamadi, S. Ebrahimi-Barough, M. Reza Nourani, M. Ali Derakhshan, V. Goodarzi, M. Sadegh Nazockdast, M. Farokhi, R. Tajerian, R. Faridi Majidi and J. Ai, J. Biomed. Mater. Res. A, 2017, 105, 1960-1972.

141 P. Sensharma, G. Madhumathi, R. D. Jayant and A. K. Jaiswal, Mater. Sci. Eng. C, 2017, 77, 1302-1315.

142 H. Mahnama, S. Dadbin, M. Frounchi and S. Rajabi, Artif. Cells, Nanomed., Biotechnol., 2017, 45, 928-935. 
143 A. A. Chaudhari, K. Vig, D. R. Baganizi, R. Sahu, S. Dixit, V. Dennis, S. R. Singh and S. R. Pillai, Int. J. Mol. Sci., 2016, 17.

144 S. J. Lee, J. Liu, S. H. Oh, S. Soker, A. Atala and J. J. Yoo, Biomaterials, 2008, 29, 2891-2898.

145 P. C. Caracciolo, M. I. Rial-Hermida, F. Montini-Ballarin, G. A. Abraham, A. Concheiro and C. Alvarez-Lorenzo, Mater. Sci. Eng. C, 2017, 75, 1115-1127.

146 E. A. Kiyotake, E. C. Beck and M. S. Detamore, Ann. N. Y. Acad. Sci., 2016, 1383, 139-159.

147 J. M. Aamodt and D. W. Grainger, Biomaterials, 2016, 86, 68-82.

148 S. Yunoki, H. Hatayama, M. Ebisawa, E. Kondo and K. Yasuda, J. Biomed. Mater. Res. A, 2015, 103, 3054-3065.

149 D. S. Musson, D. Naot, A. Chhana, B. G. Matthews, J. D. McIntosh, S. T. Lin, A. J. Choi, K. E. Callon, P. R. Dunbar, S. Lesage, B. Coleman and J. Cornish, Tissue Eng., Part A, 2015, 21, 1539-1551.

150 Y. Yu and S. Lutz, Trends Biotechnol., 2011, 29, 18-25.

151 R. D. Gupta and D. S. Tawfik, Nat. Methods, 2008, 5, 939.

152 S. A. Benner, S. O. Sassi and E. A. Gaucher, Adv. Enzymol. Relat. Areas Mol. Biol., 2007, 75, 1-132.

153 A. S. Bommarius, J. K. Blum and M. J. Abrahamson, Curr. Opin. Chem. Biol., 2011, 15, 194-200.

154 M. T. Reetz, P. Soni, L. Fernandez, Y. Gumulya and J. D. Carballeira, Chem. Commun., 2010, 46, 8657-8658.

155 I. Wu and F. H. Arnold, Biotechnol. Bioeng., 2013, 110, 18741883.

156 I. Pardo, A. I. Vicente, D. M. Mate, M. Alcalde and S. Camarero, Biotechnol. Bioeng., 2012, 109, 2978-2986.

157 C. Wang, R. Huang, B. He and Q. Du, BMC Bioinf., 2012, 13, 263.

158 I. Asial, Y. X. Cheng, H. Engman, M. Dollhopf, B. Wu, P. Nordlund and T. Cornvik, Nat. Commun., 2013, 4, 2901.
159 C. K. Savile, J. M. Janey, E. C. Mundorff, J. C. Moore, S. Tam, W. R. Jarvis, J. C. Colbeck, A. Krebber, F. J. Fleitz and J. Brands, Science, 2010, 329, 305-309.

160 M. Balamurali, D. Sharma, A. Chang, D. Khor, R. Chu and H. Li, Protein Sci., 2008, 17, 1815-1826.

161 P. J. Bujalowski and A. F. Oberhauser, Methods, 2013, 60, 151-160.

162 Y. Cao, C. Lam, M. Wang and H. Li, Angew. Chem., 2006, 118, 658-661.

163 Y. Cao and H. Li, Nat. Mater., 2007, 6, 109.

164 M. Rief, M. Gautel, F. Oesterhelt, J. M. Fernandez and H. E. Gaub, Science, 1997, 276, 1109-1112.

165 C. A. Voigt, C. Martinez, Z.-G. Wang, S. L. Mayo and F. H. Arnold, Nat. Struct. Mol. Biol., 2002, 9, 553.

166 M. M. Meyer, J. J. Silberg, C. A. Voigt, J. B. Endelman, S. L. Mayo, Z. G. Wang and F. H. Arnold, Protein Sci., 2003, 12, 1686-1693.

167 K. T. Butler, D. W. Davies, H. Cartwright, O. Isayev and A. Walsh, Nature, 2018, 559, 547.

168 T. M. Jacobs, H. Yumerefendi, B. Kuhlman and A. LeaverFay, Nucleic Acids Res., 2014, 43, e34.

169 Z. Wu, S. J. Kan, R. D. Lewis, B. J. Wittmann and F. H. Arnold, Proc. Natl. Acad. Sci. U.S.A., 2019, 116, 88528858.

170 N. C. Wu, L. Dai, C. A. Olson, J. O. Lloyd-Smith and R. Sun, Elife, 2016, 5, e16965.

171 R. J. Fox, S. C. Davis, E. C. Mundorff, L. M. Newman, V. Gavrilovic, S. K. Ma, L. M. Chung, C. Ching, S. Tam and S. Muley, Nat. Biotechnol., 2007, 25, 338.

172 P. A. Romero, A. Krause and F. H. Arnold, Proc. Natl. Acad. Sci. U.S.A., 2013, 110, E193-E201.

173 K. K. Yang, Z. Wu and F. H. Arnold, arXiv preprint arXiv:1811.10775, 2018. 